\title{
Chiral Triarylmethanes via an Enantiospecific Palladium-Catalyzed Cross-Coupling
}

Metal-Catalyzed

Asymmetric

Synthesis and

Stereoselective

Reactions

\section{Key words}

Suzuki reaction

triarylmethanes

enantiospecificity
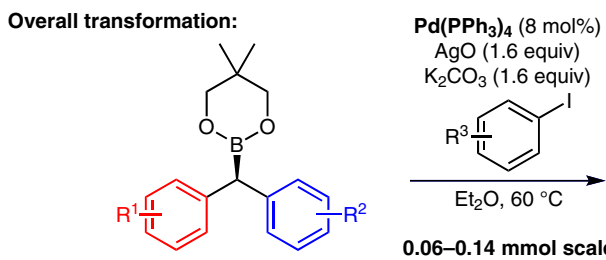

$0.06-0.14 \mathrm{mmol}$ scale
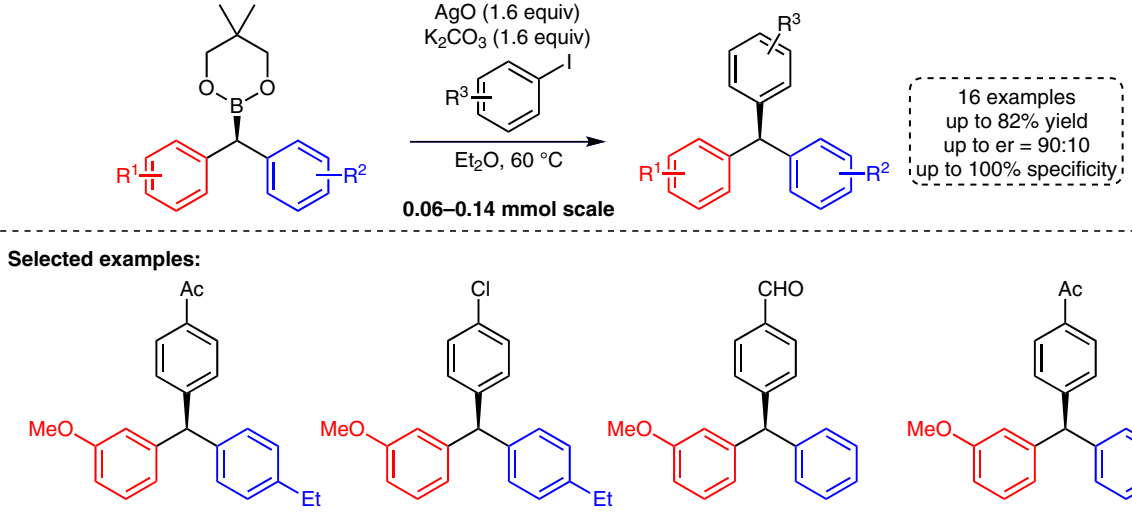

$80 \%$ yield, er $=86: 14$<smiles>Oc1cccc(C(c2ccc(F)cc2)c2ccc(Cl)cc2)c1</smiles><smiles>COc1cccc(C(c2ccccc2)c2ccc(C=O)cc2)c1</smiles><smiles>COc1cccc(C(c2ccc(C)cc2)c2ccc(F)cc2)c1</smiles>
$90 \%$ specificity

$83 \%$ yield, er $=89: 11$

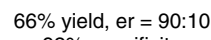
$69 \%$ yield, er $=90: 10$<smiles>Cc1ccc(C(c2ccccc2)c2ccc3ccccc3c2)cc1</smiles>
specificity<smiles>COc1cccc(C(c2ccccc2)c2ccc(Cl)cc2)c1</smiles>

$61 \%$ yield, er $=86: 14$ $89 \%$ specificity

Significance: Recently, enantioselective crosscouplings have received increased attention due to their potential for easily constructing valuable chiral molecules. However, when compared to non-enantioselective variants, there are only a limited number of reports which describe desirable levels of selectivities. The group of Crudden reports a novel route towards valuable chiral triarylmethanes via a stereospecific Suzuki crosscoupling.
Comment: The authors utilize chiral dibenzylic boronic esters (synthesis described) and aryl iodides to stereospecifically access chiral triarylmethanes using the inexpensive palladium pre-catalyst $\mathrm{Pd}\left(\mathrm{PPh}_{3}\right)_{4}$. A range of chiral boronic esters are synthesized from the benzyl carbamates with good to excellent enantiomeric ratios, which are easily converted into the target products with up to $100 \%$ stereospecificity.

SYNFACTS Contributors: Mark Lautens, David A. Petrone 